\title{
Fertility and reproductive preferences in post-transitional societies
}

John Bongaarts

Population Council

Follow this and additional works at: https://knowledgecommons.popcouncil.org/departments_sbsr-pgy

Part of the Demography, Population, and Ecology Commons, Family, Life Course, and Society Commons, and the International Public Health Commons How does access to this work benefit you? Let us know!

\section{Recommended Citation}

Bongaarts, John. 1998. "Fertility and reproductive preferences in post-transitional societies," Policy Research Division Working Paper no. 114. New York: Population Council. Version of record: https://www.jstor.org/stable/3115260 


\section{Fertility and Reproductive Preferences in Post-Transitional Societies}

\section{John Bongaarts}

1998 No. 114 


\title{
Fertility and Reproductive Preferences in Post-Transitional Societies
}

\author{
John Bongaarts
}

John Bongaarts is Vice President, Policy Research Division, Population Council. Paper prepared for the Conference on Global Fertility Transition, Bellagio, Italy, May 1998. 


\begin{abstract}
Conventional theories have little to say about the level at which fertility will stabilize at the end of the demographic transition, although it is often assumed that replacement fertility of about 2.1 births per woman will prevail in the long run. However, fertility has dropped below the replacement level in virtually every population that has moved through the transition. If future fertility remains at these low levels, populations will decline in size and will age rapidly.

This paper examines the causes of discrepancies between reproductive preferences and observed fertility. Examples of such deviations are found in many contemporary developed countries, where desired family size is typically two children while fertility is well below replacement. Six factors are identified as the causes of these discrepancies. Of these factors, the fertility-depressing impact of the rising age at childbearing is one of the most important. This factor reduces fertility only as long as the age at childbearing keeps rising. Once the mean age stops rising - as it eventually must-fertility will rise closer to the desired level of two children, because the depressing effect is then removed. The current low levels of fertility in many developed countries may therefore not be permanent.
\end{abstract}

This material may not be reproduced in any form without written permission from the author. 
The timing of the onset of contemporary fertility transitions and the pace of change during their early phases have been central concerns of researchers and policymakers in recent decades. Demographers and social scientists have studied survey data with detailed information about reproductive behaviors and attitudes of individuals in many countries. This research has provided new insights into the determinants of reproductive behavior and has contributed to the development of increasingly refined and realistic theories of fertility change. Policymakers and program managers in the developing world have been concerned about the contribution of high fertility to rapid population growth and poor reproductive health, and they have focused on implementing effective programs - in practice, mostly family planning programs - to reduce high and unwanted fertility.

Until recently, less attention had been given to determinants and consequences of fertility in post-transitional societies. Conventional theories have little to say about the level at which fertility will stabilize at the end of the transition, although it is often assumed or implied that replacement fertility of about 2.1 births per woman will prevail in the long run (Demeny 1997; Caldwell 1982). This assumption is, for example, incorporated in the population projections of the UN and World Bank (medium variants). As a result, these projections expect population size to stabilize in the long run. If fertility in contemporary post-transitional societies had indeed leveled off at or near the replacement level, there would have been limited interest in the subject because this would have been expected and concern about potential adverse consequences would have been limited. However, fertility has dropped below the replacement level — sometimes by a substantial margin - in virtually every population that has moved through the demographic transition. If future fertility remains at these low levels, populations will decline in size and will age rapidly. These demographic developments in turn are likely to have significant societal consequences (Coale 1986). Concern about these effects has led to a recent surge in scientific, programmatic, and popular interest in this topic.

This paper examines the relationship between reproductive preferences and observed fertility. Conventional fertility theories have focused on explaining how 
social and economic development and changing ideas and values determine the desired number of children (see van de Kaa 1998 for a discussion of the determinants of post-transitional preferences). These theories often assume implicitly or explicitly that couples are able to implement their preferences without much difficulty and that observed fertility is not very different from average desired family size. A declining desired family size is indeed one of the principal forces driving fertility transitions, but in reality levels of fertility often deviate substantially from stated preferences.

An example of such a deviation is found in most contemporary developed countries, where desired family size is typically two children while fertility is well below replacement. This divergence between actual fertility and desired family size is a new and unexamined phenomenon. It is of much more than theoretical interest because it raises the possibility that the low fertility observed in contemporary post-transitional societies is depressed because of temporary factors. If that is the case, fertility may be expected to rise to a level closer to the preferred level in the future, and concern over the undesirable demographic im-

plications of prolonged very low fertility in post-transitional societies may be misplaced or premature.

The causes of this discrepancy between actual and preferred fertility and its implications for future fertility trends will be examined below. After a brief overview of levels and trends in fertility and reproductive preferences at the end of the transition, the factors responsible for elevating or reducing fertility relative to desired family size will be discussed. The paper concludes with an assessment of future prospects.

\section{TRENDS IN LATE-TRANSITIONAL FERTILITY}

Fertility in the developed world reached its post-World War II maximum at 2.8 births per woman during the peak of the baby boom in the late 1950s. Steep 
declines in the 1960s and 1970s left fertility below replacement, reaching 1.7 births per woman in 1990-95. These broad trends have been observed in Europe, North America, and Australia/New Zealand (see Figure 1). In Japan fertility had already reached the replacement level in the late 1950s and it has declined further over the past quarter-century. In the late 1950s regional fertility levels ranged from a high of 3.7 births per woman in North America to a low of 2.1 in Japan, but they converged by 1980 to approximately 1.8 births per woman. Since 1980 fertility levels have diverged again, with North America's fertility rising to 2.0 births per woman while Japan and Europe have continued to drop further to about 1.5 births per woman. In the early 1990s fertility was below replacement in nearly all of the 46 countries in the developed world; the only exceptions were New Zealand (2.12), Moldova (2.15), Iceland (2.19), and Albania (2.85). ${ }^{1}$

Variations in fertility among countries within regions can be substantial. For example, within Europe fertility is lowest in the south and east, where sharp declines have occurred since 1975. Italy and Spain, with 1.24 and 1.27 births per woman, respectively, are competing for the world's record lowest level of fertility. In contrast, fertility in Northern Europe averaging (averaging 1.8 births per woman) is higher than elsewhere in the continent and it has changed relatively little over the past two decades. In a few countries fertility has actually risen since 1975, most notably in Sweden (from 1.65 to 2.01 births per woman).

Below-replacement fertility is now the norm in the developed world, but it is also observed in a small but growing number of populations elsewhere, in particular in those Southeast Asian countries where economic development has been extremely rapid in recent decades. Steep declines since 1960 have left fertility in 1990-95 at 1.94 in Thailand, 1.79 in Singapore, 1.65 in Korea, and 1.32 in Hong Kong (see Figure 2). Outside Asia, fertility was below replacement only in the Bahamas, Barbados, and Cuba, but this list is expected to grow in the future according to the 1996 revision of the UN population projections (United Nations 1996). 
Figure 1 Trends in total fertility rates in selected populations in the industrialized world, 1950-95

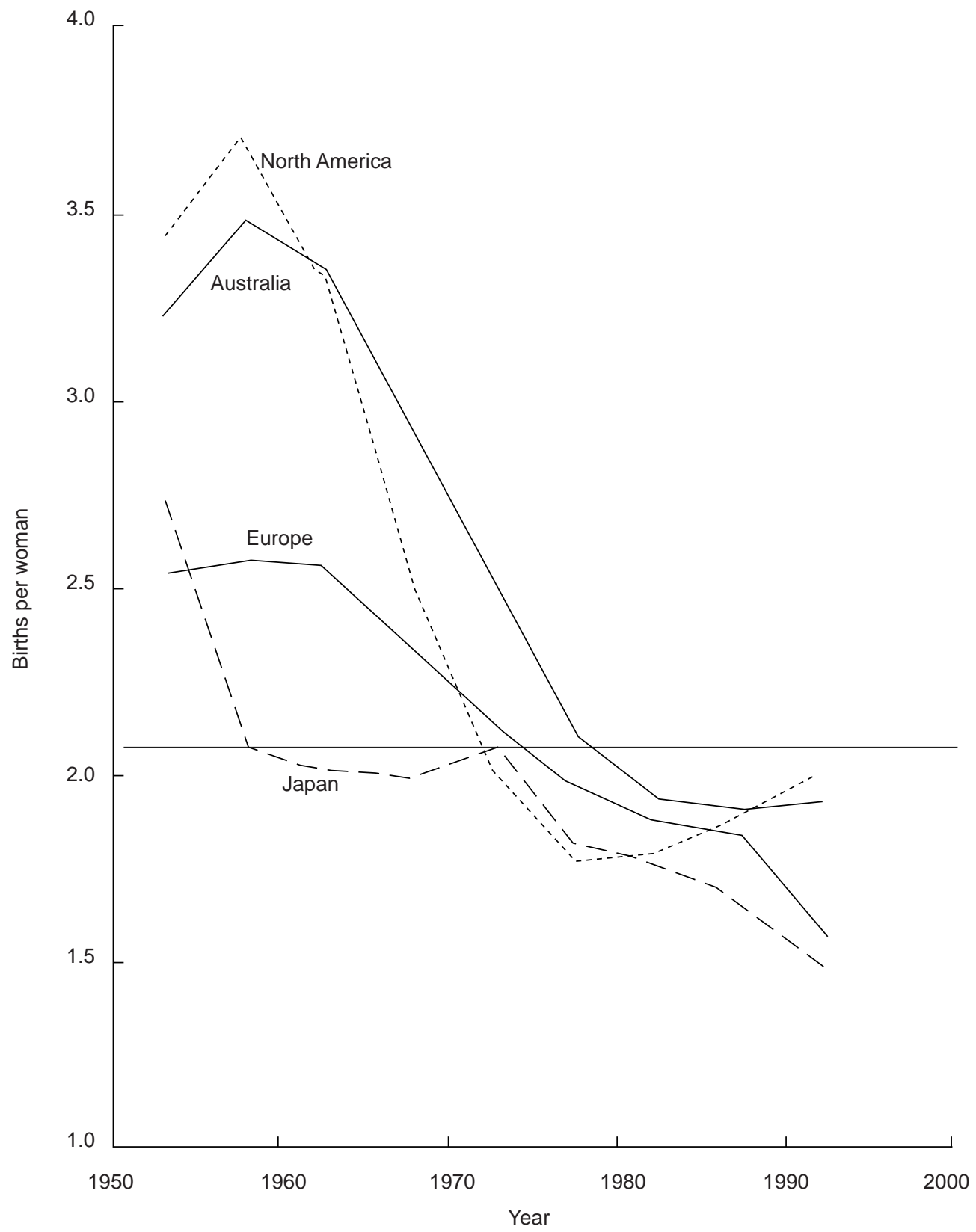

Source: United Nations (1996) 
Figure 2 Trends in total fertility rates in selected Asian populations, 1950-95

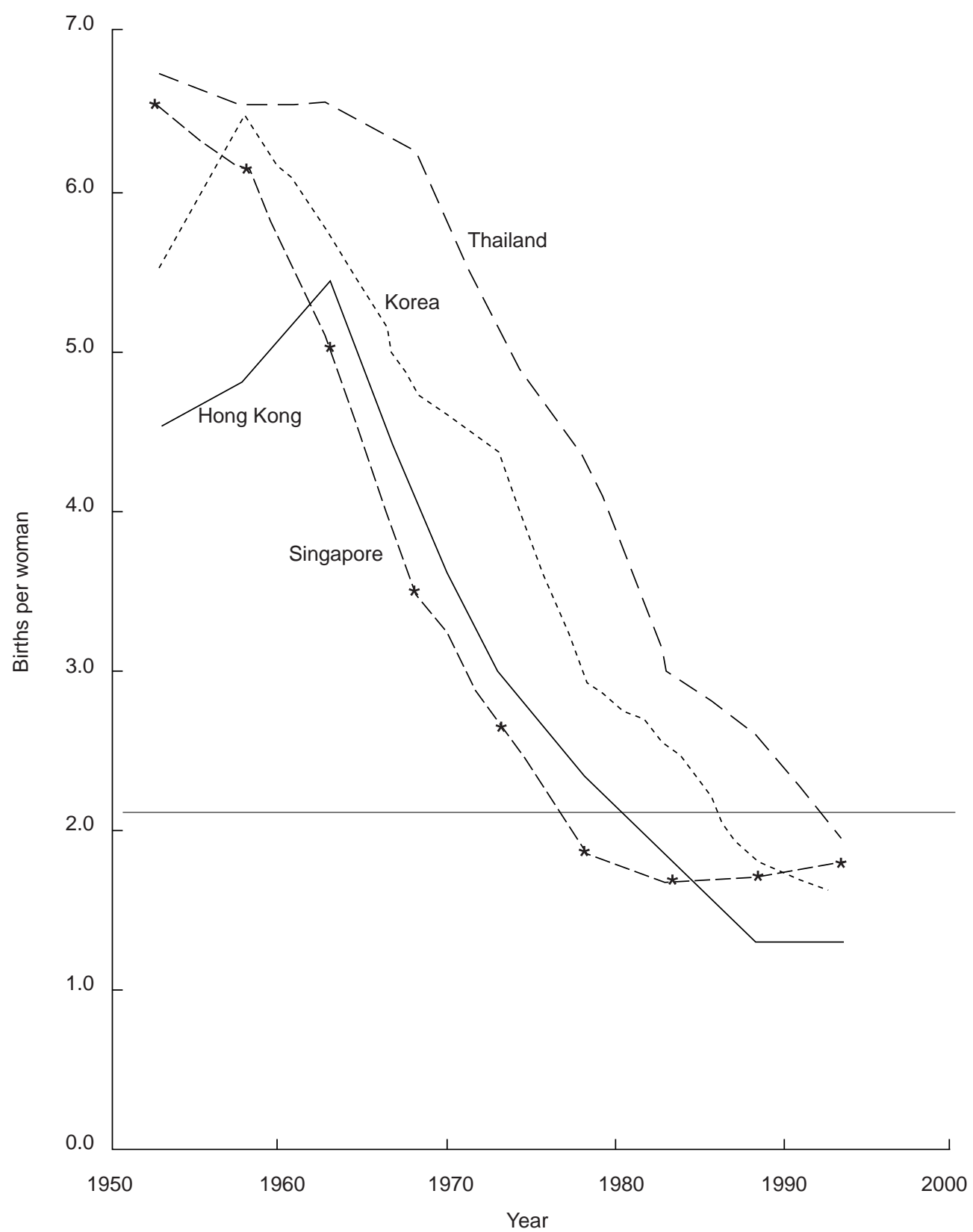

Source: United Nations (1996) 
Recent fertility trends have typically been accompanied by notable changes in attitudes and behaviors regarding sexuality, marriage, and family and household formation. These include higher levels of cohabitation, pre- and extramarital childbearing, abortion and contraception, childlessness and divorce, as well as delays in age at first marriage and first birth. These interrelated trends will not be examined in detail here, but in several instances they play key roles in explaining fertility trends; where that is the case, appropriate references will be included in the discussion below.

\section{DIVERGING TRENDS IN FERTILITY AND REPRODUCTIVE PREFERENCES}

According to a 1989 survey in 12 European countries, average desired family size (DFS) was 2.16 children per family (Lutz 1996; Eurobarometer 1991). ${ }^{2}$ Individual countries clustered tightly around this average: Ireland (2.79) and Greece (2.42) had the highest preferences, and Germany (1.97) and Spain (1.94) the lowest (see Figure 3). Surprisingly, in every country the expressed preferences substantially exceed the observed rate of childbearing as measured by the total fertility rate (TFR). Average fertility in 1989 in the European Union was 1.6 births per woman, fully 0.6 births below the average desired family size of 2.2. Similar differences between DFS and TFR are observed in contemporary developing countries at the end of their fertility transitions; Figure 3 includes recent estimates for Taiwan and Thailand.

These differences are notable because they are the opposite of what is typically found in the earlier phases of fertility transition, when observed fertility almost always exceeds preferences. The changes in these variables over time are clearly evident in the few countries, such as Thailand, where estimates of desired family size and the total fertility rate are available from a series of surveys covering most of the transition period (see Figure 4). In the late 1960s Thailand's fertil- 
Figure 3 Observed fertility and desired family size for selected countries, ca. 1990

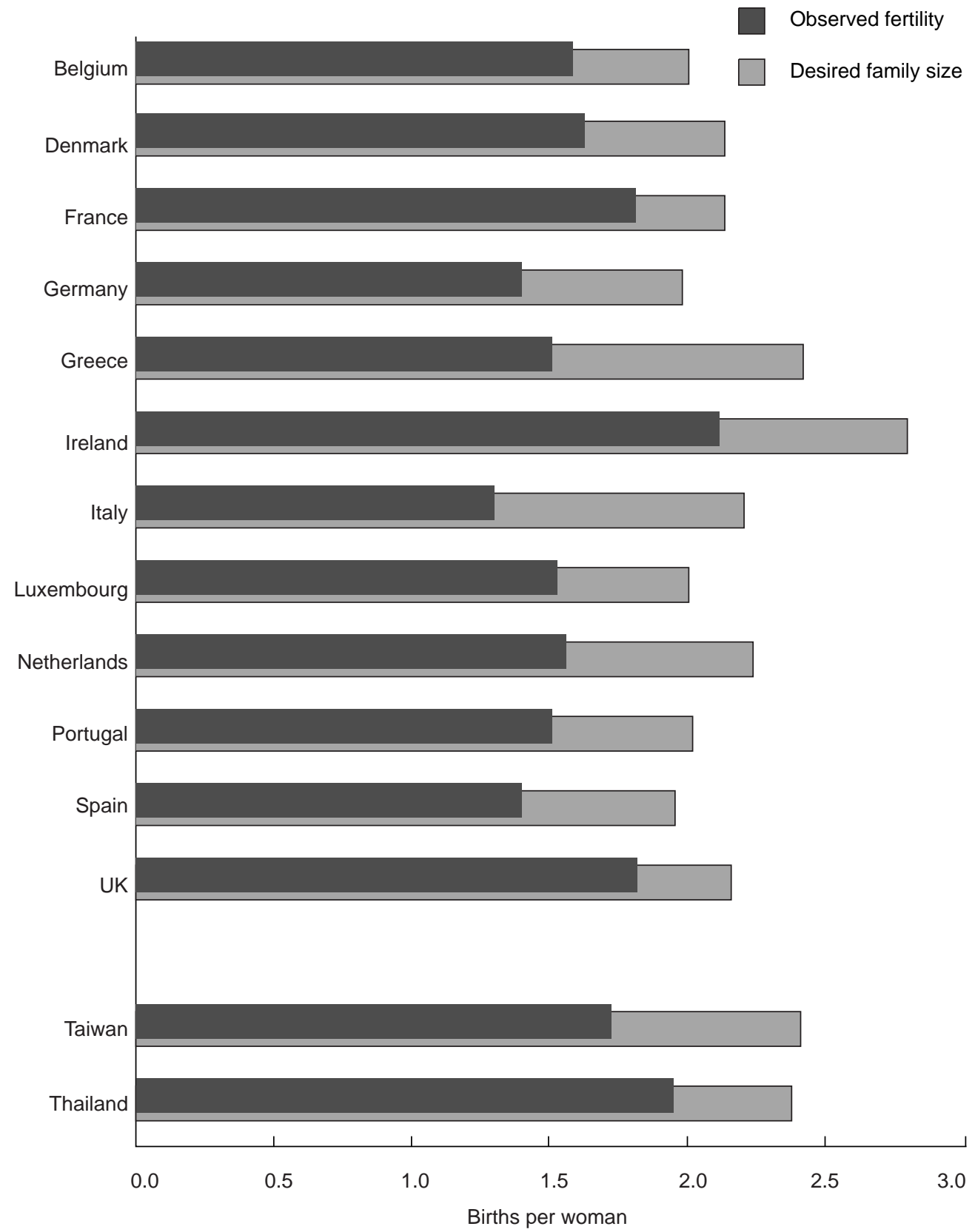

Sources: Coleman (1996); Knodel et al. (1996) 
Figure 4 Total fertility rate and desired family size, Thailand 1968-93

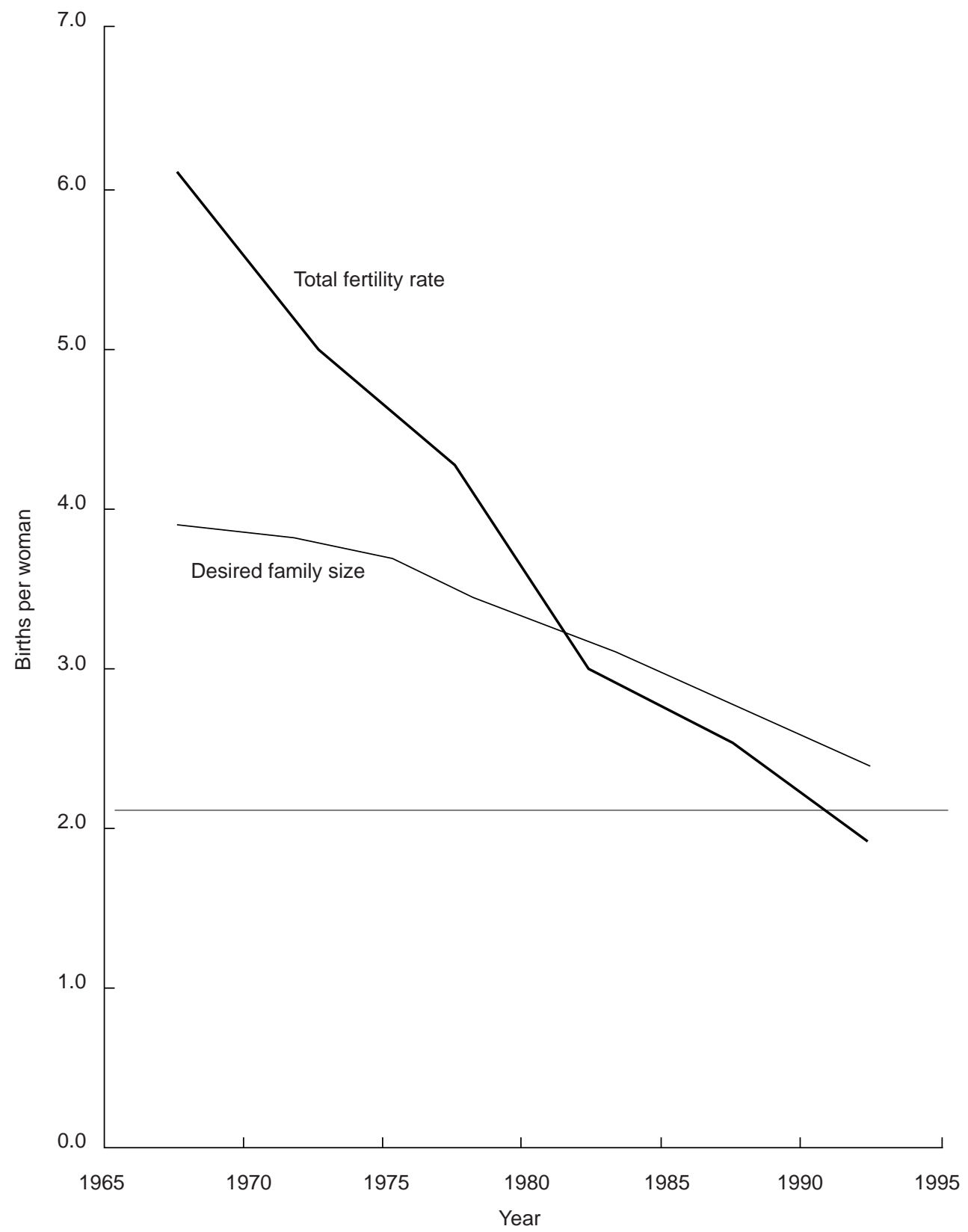

Sources: United Nations (1996); Knodel et al. (1996) 
ity still stood at 6.1 births per woman, while DFS was just 3.9 children. Since 1970 fertility has declined much more rapidly than preferences, and by the early 1990s the DFS of 2.4 children exceeded the TFR of 1.9 by 0.5 births per woman. Over this 25 -year period observed fertility dropped by 4.2 births per woman, which is more than twice the decline of 1.5 in desired family size over the same period. A broadly similar pattern is observed in Taiwan (Freedman et al. 1994)

The trends over time observed in Thailand and Taiwan are consistent with cross-sectional evidence obtained from recent surveys in 42 developing and 12 developed countries (see Figure 5). In most countries in the early or middle stages of their transitions, the observed level of fertility exceeded DFS, and in a few instances this excess reached as high as 2 births per woman. The reverse is true in countries at the end of the transition, where observed fertility was in every case lower than desired.

To explain these unexpected differences between actual and desired fertility, I now turn to a more detailed analysis of the demographic and behavioral processes that either enhance or depress fertility relative to desired family size.

\section{FACTORS ENHANCING FERTILITY RELATIVE TO DESIRED FAMILY SIZE}

The evidence reviewed in the preceding section demonstrated that during the early and midtransitional stages, observed fertility levels of populations typically exceed stated desired family sizes. Three distinct factors - unwanted fertility, child replacement, and gender preferences — can be identified as being responsible for this finding.

\section{Unwanted fertility}

In all countries where this subject has been examined, a significant proportion of women report bearing more children than they want. Detailed empirical 
Figure 5 Relationship between total fertility rate and desired family size for 42 developing and 12 developed countries

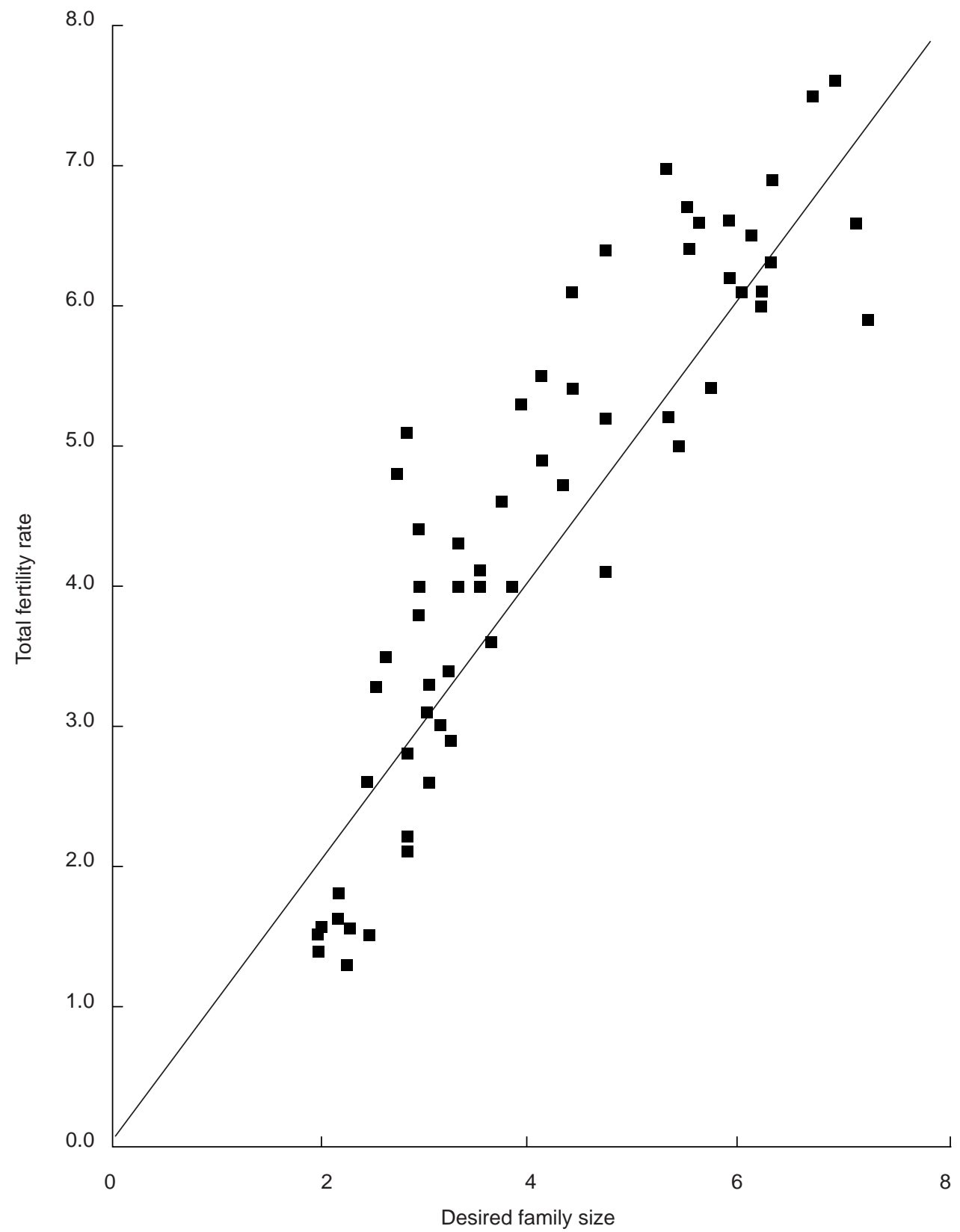

Sources: Coleman (1996); Westoff (1991); Westoff et al. (1987) 
evidence for unwanted childbearing in recent decades is available for a large number of developing countries from fertility surveys such as the DHS and WFS (Westoff 1991; Bankole and Westoff 1995). A recent analysis of levels and trends in unwanted childbearing in 20 developing countries estimated that on average 22 percent of fertility was unwanted ca. 1990 (Bongaarts 1997). The level of unwanted childbearing was found to vary systematically over the course of the fertility transition. In the most traditional pretransitional societies, preferences and fertility are often both high so that unwanted childbearing is relatively uncommon. However, with the onset of the fertility transition, unwanted fertility typically rises substantially. This rise is explained by a decline in desired family size, which leads to an increase in the proportion of women who are at risk of having more births than they wish. Resort to the practice of contraception and induced abortion is typically insufficiently rapid to avoid a rise in unwanted childbearing. Reasons for nonuse of contraception include lack of access to contraceptive services, fear of side effects, and opposition of husband or others. This incomplete control over the reproductive process leads to high levels of unwanted fertility, usually exceeding 1 birth per woman on average in midtransitional societies. Finally, in the last part of the transition unwanted fertility declines again as couples are increasingly able to implement their preferences by practicing contraception effectively and/or by resorting to induced abortion.

Unfortunately, estimates of unwanted fertility are not readily available for developed countries, except in the United States. A 1995 US survey found that 10.1 percent of births in the early 1990s were unwanted, down slightly from 12 percent in 1988 (Abma et al. 1997). Comparable estimates are not available for European countries, but Westoff et al. (1987) used an indirect procedure to estimate unwanted childbearing levels in six European countries ca. 1981. The unwanted proportion of fertility ranged from 11.2 percent in France to 7.5 percent in the Netherlands. As in the United States, these proportions are presumably declining slowly over time as the use of contraception and induced abortion rises. 
Unwanted childbearing is the main reason why observed fertility exceeds DFS in many developing countries. This conclusion is based on a comparison of the wanted component of the TFR (WTFR) (i.e., the TFR from which unwanted births have been excluded) with the DFS for 45 countries in Figure 6. This comparison shows that the wanted TFR is almost invariably somewhat below the DFS, which is the reverse of the pattern observed in Figure 5. This finding implies that the unwanted component of the TFR was responsible for most of the excess of the TFR over the DFS in Figure 5. In the few developed countries where fertility was already below DFS, the removal of unwanted births leads to a modestly larger discrepancy between observed and desired fertility.

The decline in unwanted fertility toward the end of the fertility transition explains in part why fertility drops more rapidly than the DFS late in the transition. For example, in Thailand estimates from the 1975 WFS and the 1987 DHS are as follows (Westoff 1991):

\begin{tabular}{lcr}
\hline & $\mathbf{1 9 7 5}$ & $\mathbf{1 9 8 7}$ \\
\hline TFR & 4.3 & 2.2 \\
Wanted TFR & 3.2 & 1.8 \\
Unwanted TFR & 1.1 & 0.4 \\
DFS & 3.7 & 2.8 \\
\hline
\end{tabular}

Between 1975 and 1987 the unwanted TFR declined by more than half, from 1.1 to 0.4 births per woman. As a result the decline in the wanted TFR (from 3.2 to 1.8 ) is much less steep than for the TFR (from 4.3 to 2.2).

Clearly, a significant part of the excess of observed over preferred fertility found in midtransitional societies is attributable to substantial levels of unwanted childbearing. Under certain conditions two other factors, child mortality and gender preferences, also play a role in elevating fertility. These are discussed next. 
Figure 6 Relationship between wanted total fertility rate and desired family size for 42 developing and 3 developed countries

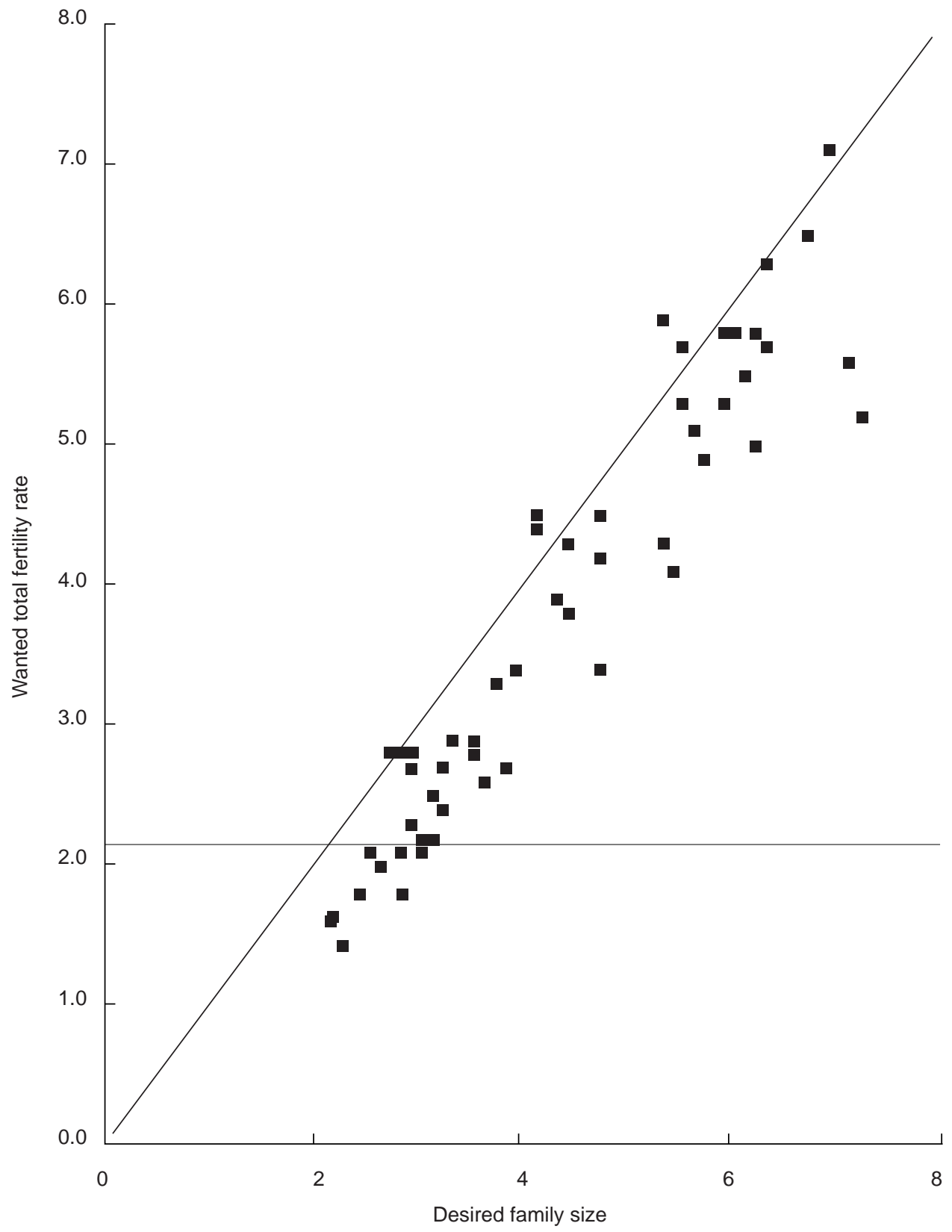

Sources: Coleman (1996); Westoff (1991); Westoff et al. (1987) 


\section{Replacement of deceased children}

Despite the best efforts of many analysts, the impact of trends in child mortality on reproductive behavior remains incompletely understood (Cohen and Montgomery 1997).

Considerable effort has been devoted to identifying and measuring the specific societal and behavioral mechanisms through which mortality potentially affects fertility (Preston 1978; Lloyd and Ivanov 1988; Cohen and Montgomery 1997), but empirical support for several of these proposed mechanisms remains weak. There are two cases where the evidence is clear: the "lactation-interruption" effect (the death of an infant interrupts the anovulatory interval following a birth, so that the mother is exposed sooner to the risk of pregnancy than would have been the case had the child survived) and the "replacement" effect (parents replace children that have died). The lactation-interruption effect is largest in traditional societies with long durations of breastfeeding or postpartum abstinence and with limited use of contraception. The replacement effect is strongest in populations where the deliberate control of fertility is extensive, and it is therefore of greater interest than the lactation-interruption effect for present purposes. Although deliberate replacement is more prevalent in the later stages of the fertility transition, it is never complete and most studies find that only up to about half of dead children are replaced (Lloyd and Ivanov 1988).

When replacement occurs it increases the number of births a couple has without changing the desired family size, and it is therefore one of the reasons why the former might exceed the latter. While there is no doubt that replacement takes place in many families that experience the death of a child, it has only a small impact on fertility in late-transitional societies because few children die. In contemporary developed countries infant mortality averages 9 deaths per 1000 births (i.e., less than 1 percent). In such cases even complete replacement would raise fertility by only about 0.02 births per woman, which is small enough not to be of practical significance at the population level. 


\section{Gender preferences}

When stating a preference for a family of a particular size, a couple may have a specific gender composition in mind (e.g., two sons or at least one son and one daughter). In such cases parents may continue to have births after they have reached their desired number of children if their preferred gender composition has not been achieved. The existence of gender preferences therefore leads to higher fertility than would be the case in their absence, except in societies where parents do not control their fertility.

Questions on the desired number of sons and daughters are not always included in surveys such as the DHS and WFS. However, evidence for gender preferences can be inferred from the effects of the gender composition of a woman's current family on the desire to continue childbearing. For example, Figure 7 plots the proportion who want another child among women with two children, comparing women with two sons, women with a son and a daughter, and women with two daughters in different world regions. Several conclusions can be drawn from this evidence. First, the desire for more births among women with two children varies widely among regions. It is highest in sub-Saharan Africa, intermediate in Asia and the Middle East, and lowest in Latin America. As expected, these differences are explained by regional differences in desired family size (Bankole and Westoff 1995). Second, son preference (as measured by the ratio of the proportion wanting more births among women with two daughters to the proportion wanting more among women with two sons, $2 \mathrm{D} / 2 \mathrm{~S}$ ) is highest in Asia and the Middle East and essentially nonexistent in sub-Saharan Africa and Latin America. In fact, in Latin America there is a slight tendency to prefer girls over boys. Among individual countries, son preference is highest in India, with a $2 \mathrm{D} / 2 \mathrm{~S}$ ratio of 2.6, and ratios exceeding 1.5 were found in Bangladesh, Nepal, and Turkey (Arnold 1997). Daughter preference is highest in Colombia and Trinidad and Tobago. Third, the $U$ shaped patterns observed in Figure 7 are evidence of a desire for balance in the number of boys and girls. This implies that even in the 
Figure 7 Desire for more children among women with 2 children, by region and family composition

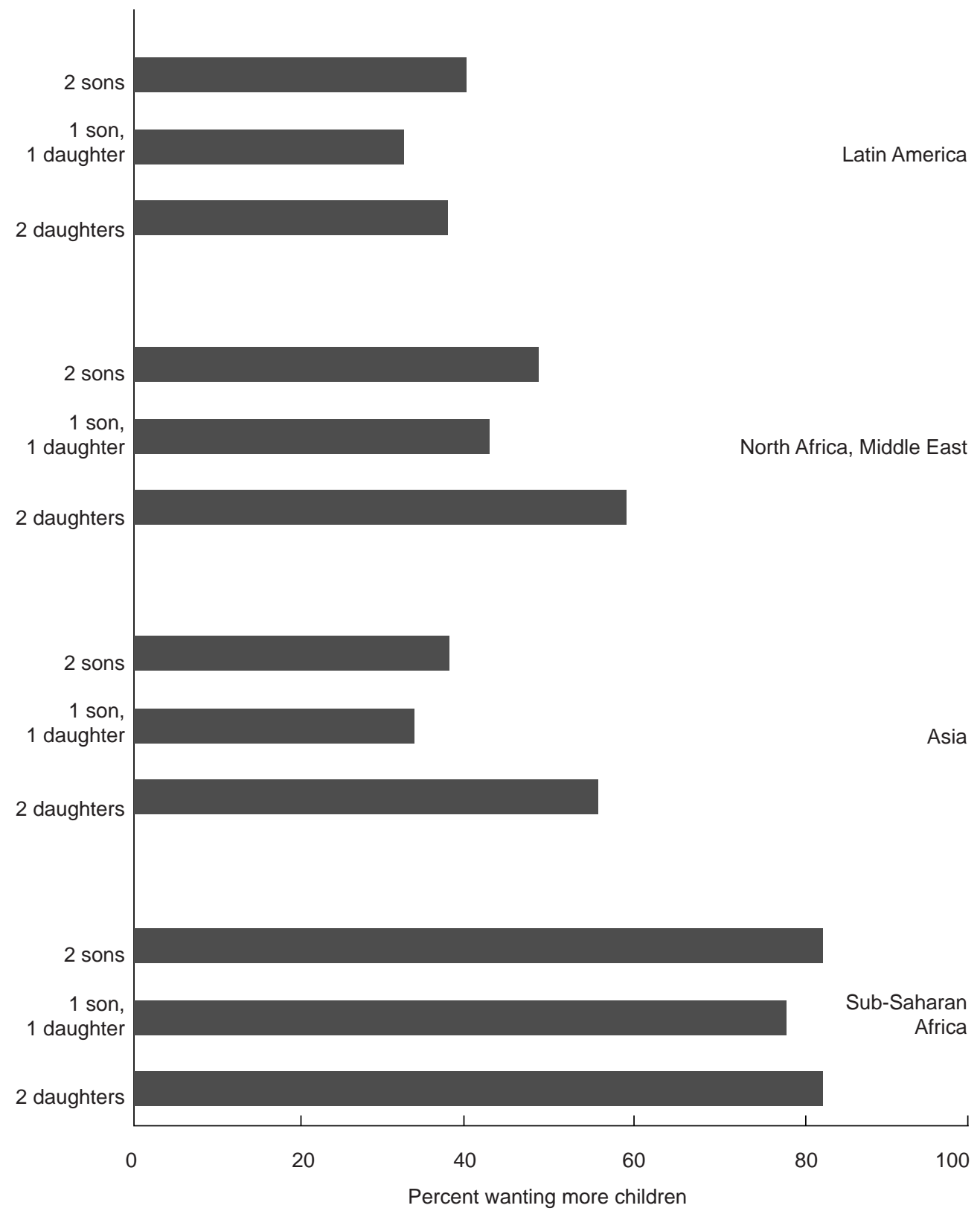

Source: Arnold (1997) 
absence of son or daughter preference, women would rather have a family with at least one child of each gender than a family that consists solely of sons or daughters. As a result, among women with two children those with one son and one daughter are most likely to stop childbearing.

The fertility effect of these gender preferences in a particular society is not easily estimated because it depends on the structure of parental preferences for gender composition and size of their families, on the way parents reconcile conflicting preferences for gender composition and size, on the degree to which these preferences are implemented by the effective use of birth control, and, in a few countries, on the extent of reliance on sex-selective abortion. In general, the fertility effect is small or nonexistent in countries with high fertility and low levels of contraceptive use. The impact rises over the course of the fertility transition as parents become increasingly effective in achieving their reproductive goals. A few recent studies provide quantitative estimates of the degree to which fertility is inflated because of gender preferences: 8 percent in Bangladesh (Chowdhury and Bairagi 1990), 8.4 percent in India (Mutharayappa et al. 1997), and 13.5 percent in Korea (Park and Cho 1995). Estimates for states of India range from 4.5 percent in Uttar Pradesh (a state with a low level of contraceptive prevalence) to 24.6 percent in Himachal Pradesh (with one of the highest prevalence levels). These estimates of the fertility effects of gender preferences are large enough to have significant demographic consequences in post-transitional societies.

\section{FACTORS REDUCING FERTILITY RELATIVE TO DESIRED FAMILY SIZE}

As populations progress through the last stages of the transition, observed fertility typically moves from a level above desired family size to a level below it. Part of the explanation for this trend is the attenuation of the three factors that inflate fertility during the early phases of the transition (see preceding section). 
In addition, three other factors-rising age at childbearing, involuntary infertility, and competing preferences-depress fertility relative to desired family size.

\section{Rising age at childbearing}

The total fertility rate is by far the most widely used indicator of aggregate period fertility and is therefore used throughout this paper to measure levels and trends in the fertility of populations. Despite the apparent simplicity and wide availability of this indicator, it is a complex measure that is subject to misinterpretation. The main problem is that the fertility level observed in a given year or period is affected by ongoing changes in the timing of childbearing (Ryder 1959, 1980). The best-known example of this often unappreciated effect is the baby boom in the 1950s in the United States, which was partly attributable to a decline in the mean age at childbearing following World War II. As successive cohorts started bearing children at younger ages, their births overlapped in the same time periods, thus boosting observed period fertility. The opposite effect is less familiar but of special interest for present purposes: increases in the age at childbearing deflate the TFR because births to successive cohorts are spread over a longer time period. The latter distortion has dominated in recent decades, since the age at onset of childbearing has risen in many late-transitional countries worldwide since the 1970s (Council of Europe 1996; Singh et al. 1996). For example, as shown in Figure 8, sharp increases in the mean age at first birth have occurred in several countries of Europe and in the US. This trend implies that recent fertility (as measured by the TFR) in these countries has been lower than it would have been without this "tempo" effect.

Although demographers have long been aware of the distortions caused by changes in the timing of childbearing, there is no agreed-upon methodology for removing tempo effects from observed total fertility rates. Ryder, who has written extensively on this subject, has proposed "translation" equations to calculate 
Figure 8 Trends in mean age at first birth in selected populations, 1970-95

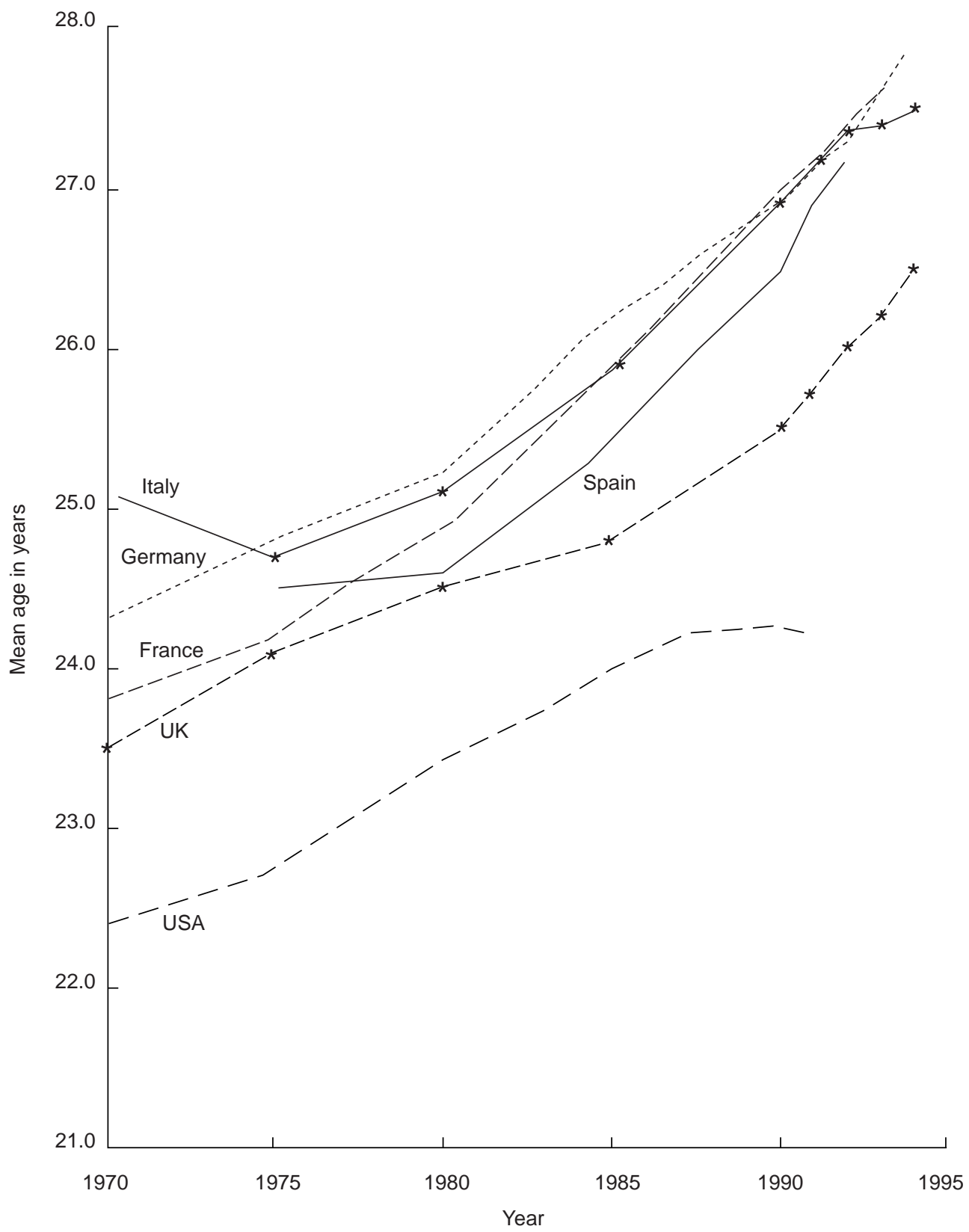

Source: Council of Europe (1996) 
the period fertility measures from corresponding cohort measures when the timing of cohort fertility is changing (Ryder 1956, 1964, 1983). These procedures have not found wide acceptance for two main reasons. First, in his work on the translation issue Ryder assumes that the tempo and quantum of cohort fertility are the determinants of the TFR and other period fertility measures. However, extensive empirical analysis of this issue has demonstrated that this is not the case (Brass 1974; Page 1977; Foster 1990; Pullum 1980; Ní Bhrolcháin 1992). For example, Brass (1974) concluded that cohort completed fertility revealed no significant feature that distinguishes it from time averages of period indices. A recent review of this literature by Ní Bhrolcháin (1992) reached a similar conclusion. Second, the two dimensions of aggregate cohort fertility-quantum and tempo-are in practice not independent. When cohorts reduce their fertility they do so primarily by reducing childbearing at higher birth orders. As a result, the mean age at childbearing for all births to the cohort declines even if the timing of individual births does not change. In other words, a decline in the cohort quantum leads to changes in the cohort's mean age at childbearing that do not represent true tempo effects. Ignoring this effect-as Ryder does in much of his writing-therefore gives biased results except when cohort fertility is constant. Fortunately, this second problem can be solved by analyzing fertility trends separately for each birth order rather than for overall fertility. This option was actually mentioned by Ryder (1959), but for some reason he largely ignored order specificity in subsequent work on the translation problem.

An alternative approach to removing potential distortions from the period total fertility rates is through the application of life table procedures. Whelpton (1954) first proposed the calculation of revised total fertility rates using a life table based on age-parity-specific birth rates. This early work provided the foundation for further research in recent decades on alternative ways to standardize fertility measures-for example, not only by age and parity but also by duration 
since last birth (Henry 1980; Feeney and Yu 1987; Feeney et al. 1989; Ní Bhrolcháin 1987; Rallu and Toulemon 1994). Unfortunately, these life table procedures do not directly address the distorting effects of changes in the timing of childbearing. Tempo changes influence the age-specific fertility rates as well as age-parity-specific and age-duration-specific birth rates. The results from the life tables are therefore not free of tempo effects.

In a recent study Bongaarts and Feeney (1998) propose a new procedure for removing tempo effects from the TFR. The approach is an outgrowth of Ryder's original translation equation. The above objections to Ryder's approach are removed by assuming that fertility is strictly period driven and that cohorts have no independent explanatory power, and by applying adjustments to the order components of the total fertility rate rather than to the total fertility rate itself. Under these conditions, it is possible to estimate the adjusted (i.e., tempo-free) total fertility rate in any given year (or period) from the conventional TFR at each birth order with the following equation:

$$
\mathrm{TFR}_{\mathrm{O}}=\mathrm{TFR}_{\mathrm{O}} /\left(1-\mathrm{m}_{\mathrm{O}}\right)
$$

where

$\mathrm{TFR}_{\mathrm{O}}=$ observed total fertility rate component for birth order o

TFR ${ }_{\mathrm{O}}=$ adjusted total fertility rate component for birth order $\mathrm{o}$ $\mathrm{m}_{\mathrm{O}}=$ annual rate of change in mean age of age-specific fertility schedule, birth order o.

In other words, by dividing the observed total fertility rate by $(1-\mathrm{m})$ at any given birth order, one obtains the total fertility rate that would have been observed had there been no change in the timing of childbearing.

Summing results for different birth orders gives the overall tempo-free total fertility rate:

$$
\mathrm{TFR}^{\prime}=\Sigma \mathrm{TFR}^{\prime}{ }_{\mathrm{O}}
$$


According to these equations, an annual increase of one-tenth of a year in the mean age at childbearing $\left(\mathrm{m}_{\mathrm{o}}=0.1\right)$ reduces $\mathrm{TFR}_{\mathrm{o}}$ by 10 percent below its tempo-free level (because TFR $=\operatorname{TFR}_{0}{ }_{0}(1-0.1)$ ). Similarly, an annual decline in the mean age at a rate of just 0.1 years per year $\left(m_{0}=-0.1\right)$ inflates $T_{F R}$ by 10 percent. Clearly, modest changes in the timing of childbearing at any birth order can produce substantial changes in observed fertility.

Estimates of the tempo-free TFR' for the period 1985-89 for selected populations were obtained with the above procedure; the results of this exercise are summarized in Table 1. In each of the seven countries included in this table, the elimination of the tempo effect raised fertility (TFR'>TFR); this is as expected from the rising age at childbearing in these populations. The adjustment for the tempo effect ranged from more than 0.35 births per woman in the Netherlands, France, and Taiwan to a low of 0.08 in the US. This low estimate for the US is attributable to the fact that the mean age at first birth stopped rising at the end of the 1980s (see Figure 8). For the seven countries as a whole, removal of the tempo effect led to an increase from the average observed TFR of 1.78 births per

Table 1 Total fertility rate with and without adjustment for tempo effect, 1985-89

\begin{tabular}{lrrr}
\hline & TFR & TFR' (adjusted) & Tempo effect \\
\hline France & 1.81 & 2.21 & 0.40 \\
Netherlands & 1.54 & 1.90 & 0.36 \\
Norway & 1.78 & 2.05 & 0.27 \\
Sweden & 1.90 & 2.00 & 0.10 \\
UK & 1.80 & 1.92 & 0.12 \\
US & 1.90 & 1.98 & 0.08 \\
Taiwan & 1.74 & 2.14 & 0.40 \\
Average & 1.78 & 2.03 & 0.25 \\
\hline
\end{tabular}

Source: see text. 
woman to an adjusted TFR' of 2.03 births per woman, which is very close to the replacement level. In France and Taiwan the adjusted TFR' actually exceeded replacement. In this set of populations the fertility-inhibiting effect of the rising age at childbearing is primarily responsible for the fact that observed fertility is below replacement.

\section{Involuntary infertility}

An individual who wishes to have a certain number of children may be unable to achieve his or her reproductive objective because of a number of involuntary factors. Involuntary childlessness can be the result of a) Inability to find a suitable partner. This has historically been a key cause of relatively high levels of childlessness in Europe, as well as in selected populations elsewhere (e.g., Philippines). b) Marital disruption. A union may end in divorce or with the death of a partner before any children have been born. c) Physiological sterility. A small proportion of otherwise healthy couples is unable to conceive or have offspring because of biological abnormalities in either partner. This proportion is thought to be relatively invariant among populations and rises with the age of the female partner from about 3 percent in the early 20s to about 20 percent in the late 30 s and near 100 percent by age 50 (Bongaarts and Potter 1983). d) Disease-induced sterility. Sexually transmitted diseases such as untreated gonorrhea can lead to sterility. As a consequence, substantial levels of involuntary childlessness are found in societies where the prevalence of sexually transmitted diseases is high (Gray 1983; WHO 1995).

Among individuals who have already had a child the intention to have additional children may be frustrated for most of the same reasons that lead to involuntary childlessness. Further childbearing can be prevented by a divorce or death that ends the partnership, or by the onset of physiological or disease-induced sterility. The precise extent of involuntary family limitation is difficult to measure because it is not readily separated from voluntary limitation of child- 
bearing. In general, involuntary infertility is greatest in populations with late ages at first union, high proportions never entering unions, high rates of divorce or widowhood, large desired family sizes, and high levels of prevalence of sexually transmitted diseases.

\section{Competing preferences}

In most fertility surveys small proportions of women report that they do not want any more children even though they have not yet attained their desired family size (Bongaarts 1991). The principal reason for this apparent inconsistency is probably the presence of economic, social, health, or other factors that cause a woman to want to stop childbearing sooner than she would under more favorable circumstances. This finding suggests that responses to questions about desired or ideal family size do not produce completely accurate estimates of the current demand for children. Apparently some women report a number closer to the one they would prefer under circumstances other than those they have actually experienced or expect to experience.

\section{TOWARD A SYNTHESIS}

Together the above six factors are responsible for the differences between the TFR and the DFS of populations. The role of the different effects can be quantified with the following general equation:

$$
\mathrm{TFR}=\mathrm{DFS} * \mathrm{~F}_{\mathrm{u}} * \mathrm{~F}_{\mathrm{g}} * \mathrm{~F}_{\mathrm{r}} * \mathrm{~F}_{\mathrm{t}} * \mathrm{~F}_{\mathrm{i}} * \mathrm{~F}_{\mathrm{c}} * \mathrm{E},
$$

where the $\mathrm{F}$ variables represent the multiplicative effect on fertility of each factor: $F_{u}$ represents the effect of unwanted fertility, $F_{g}$ of gender preferences, $F_{r}$ of child replacement, $F_{t}$ of tempo changes, $F_{i}$ of involuntary family limitation, and $\mathrm{F}_{\mathrm{c}}$ of competing preferences; $\mathrm{E}$ is an error term. Each multiplicative factor is estimated as the ratio of the TFR in the presence and the absence of the corresponding fertility-enhancing or -inhibiting effect, while holding all other factors 
constant. A factor equals 1 if there is no effect, but in general the factors will deviate from 1, with the difference indicating their influence on fertility. Based on the preceding discussion it can be stated that $\mathrm{F}_{\mathrm{u}}, \mathrm{F}_{\mathrm{g}}$, and $\mathrm{F}_{\mathrm{r}}$ usually exceed 1 while $\mathrm{F}_{\mathrm{i}}$ and $\mathrm{F}_{\mathrm{c}}$ are normally below 1 . When the age at childbearing rises, $\mathrm{F}_{\mathrm{t}}<1$; when it declines, $\mathrm{F}_{\mathrm{t}}>1$.

To undertake a comprehensive analysis of the relationship between actual and preferred fertility, one would need accurate estimates of each of the six factors. This is not possible at present because there is no agreed-upon methodology for measuring several of the factors, for example, gender preferences, child replacement, and involuntary family limitation. In addition, even when a methodology exists for measuring a specific factor, the data required for its application are sometimes lacking in a particular population. A full discussion of these methodological, measurement, and data issues is beyond the scope of this paper.

Despite these problems, it is possible to make progress by focusing on the role of two factors - unwanted childbearing and tempo changes - that are clearly important for understanding trends in late-transitional fertility and that are quantifiable with available procedures. For this purpose a reduced version of equation (2) is used:

$$
\mathrm{TFR}=\mathrm{DFS} * \mathrm{Fu} * \mathrm{Ft} * \mathrm{~F}^{\prime},
$$

where $F^{\prime}$ represents the joint effects of $F_{g}, F_{r}, F_{i}, F_{c}$, and $E$.

Application of equation (3) is feasible if estimates of TFR, TFR', WTFR, and DFS are available (see earlier discussion of sources for these variables). In populations for which these measures are available the two factors $F_{u}$ and $F_{t}$ can be calculated with

$$
\begin{aligned}
& \mathrm{F}_{\mathrm{u}}=\text { TFR/WTFR } \\
& \mathrm{F}_{\mathrm{t}}=\text { TFR/TFR' }
\end{aligned}
$$

and $\mathrm{F}^{\prime}$ can be calculated as a residual

$$
\mathrm{F}^{\prime}=\mathrm{TFR} /\left(\mathrm{DFS} * \mathrm{~F}_{\mathrm{u}} * \mathrm{~F}_{\mathrm{t}}\right) \text {. }
$$


To illustrate an application of the analytic framework represented by equation (2), I rely on two hypothetical examples: one population (A) representing a posttransitional society (not unlike Europe today) and the other (B) representing a midtransitional society (not unlike Thailand in the 1970s). Illustrative values for fertility and the multiplicative factors are presented in Table 2 . It is assumed that in population $\mathrm{A}$ the $\mathrm{TFR}=1.6$ births per woman and $\mathrm{DFS}=2.1$ births per woman, while in population $\mathrm{B}$ TFR $=4.3$ births per woman and DFS $=3.7$. To simplify the subsequent analysis it is helpful to focus on the ratio of TFR to DFS

$$
\mathrm{TFR} / \mathrm{DFS}=\mathrm{F}_{\mathrm{u}} * \mathrm{~F}_{\mathrm{t}} * \mathrm{~F}^{\prime} .
$$

The puzzle to be solved is why this ratio is substantially less than 1 (1.6/ $2.1=0.76)$ in population $A$ and why it exceeds 1 in population $B(4.3 / 3.7=1.16)$. The solution in general lies in the fact that this ratio equals the product of the three factors $F_{u}, F_{t}$, and $F^{\prime}$ and that in population $A$ the product of the fertilityreducing factors exceeds the product of the fertility-enhancing factors while the reverse is the case in population B. Specifically, in population A the positive

Table 2 Illustrative values for TFR, DFS and the factors $F_{u}, F_{t}$, and $F^{\prime}$ for two hypothetical populations

\begin{tabular}{lcc}
\hline & $\begin{array}{c}\text { Population A } \\
\text { Post-transitional }\end{array}$ & $\begin{array}{c}\text { Population B } \\
\text { Midtransitional }\end{array}$ \\
\hline TFR & 1.60 & 4.30 \\
DFS & 2.10 & 3.70 \\
TFR/DFS & 0.76 & 1.16 \\
$F_{u}$ & 1.10 & 1.34 \\
$F_{t}$ & 0.80 & 1.00 \\
F' & 0.87 & 0.87 \\
\hline
\end{tabular}

Source: see text. 
effect of unwanted fertility $\left(\mathrm{F}_{\mathrm{u}}=1.1\right)$ is more than offset by the joint inhibiting effects of tempo $\left(F_{t}=0.8\right)$ and the residual $\left(F^{\prime}=0.87\right)$. In contrast in population $B$ the effect of unwanted childbearing $\left(\mathrm{F}_{\mathrm{u}}=1.34\right)$ exceeds the offsetting impact of the residual factors $\left(F^{\prime}=0.87\right)$, assuming no tempo effect in this case.

For these two hypothetical populations the effects of the factors on the difference between fertility and DFS are clear. In the midtransitional population $\mathrm{B}$, both the effect of unwanted fertility $\left(\mathrm{F}_{\mathrm{u}}\right)$ and the timing effect $\left(\mathrm{F}_{\mathrm{t}}\right)$ are higher than in late-transitional population A. This explains why fertility in B exceeds DFS while the reverse is found in A. Similar analyses of trends in the factors can explain trends in TFR and DFS over time in other populations, and these analyses will presumably also demonstrate the key roles played by declining unwanted fertility and by tempo effects at the end of the fertility transition.

\section{Discussion: Future Prospects}

The future course of fertility in countries where it is already at or below replacement is one of the most controversial issues in contemporary demography. One group of analysts points to the indisputable fact that fertility has dropped below replacement in virtually all countries that have reached the end of the transition. This is the case in Europe and North America, where fertility has been below replacement since the mid-1970s, as well as in the most-developed countries in the South, such as Hong Kong, Korea, Singapore, Taiwan, and Thailand. In a few instances fertility has leveled off above replacement (e.g. Argentina and Chile), but these are exceptions. According to this school of thought, replacement fertility is a theoretical threshold that has little or no meaning for individual couples building their families, and below-replacement fertility is expected to be the norm in post-transitional societies (Demeny 1997).

A contrary view is held by analysts who believe that the current low levels of post-transitional fertility are a temporary phenomenon and that concerns about 
imminent population declines caused by low fertility are misplaced in some countries (Le Bras 1991; Knodel et al. 1996). This perspective is supported by data on DFS, which has remained near or above two children in all societies for which measures are available. In this view, the observed below-replacement fertility is largely attributable to ongoing shifts in the timing of childbearing. Once this rise ends-as it eventually must - the corresponding fertility-depressing effect stops, thus bringing fertility back up, presumably to near replacement.

These competing views are both partly valid, but incomplete. The actual situation is more complex and a full assessment requires a separate examination of trends in DFS as well as in each of the six factors linking fertility to DFS.

Desired family size. Whether DFS remains at or drops below 2 is the most crucial issue determining post-transitional fertility. Conventional fertility theories are essentially silent on this topic. The empirical record suggests resistance to declines in DFS below 2 children (typically couples want 1 boy and 1 girl), and for the moment it appears reasonable to assume that DFS will level off at about 2. However, in view of the high cost of children and the trend toward consumerism and individualism, it would not be surprising if DFS did fall further (Lutz 1996; van de Kaa 1987). The levels of DFS that will prevail when societies complete their transitions will no doubt vary systematically among populations because of differences in socioeconomic and cultural factors as well as social policies.

Unwanted fertility. In the later phases of the transition the rate of unwanted childbearing typically declines as a consequence of greater reliance on effective contraception and induced abortion among couples who want to avoid pregnancy. This trend is likely to persist and it will be aided by the expected availability of new contraceptive technology. New methods will make contraceptive use more convenient and safer and it should increase use and reduce contraceptive failure. Reliance on induced abortion probably will also rise as more convenient medical abortifacients are made accessible in more countries. As a result, couples' ability 
to limit fertility to desired levels will almost certainly improve in coming years, and unwanted childbearing will become correspondingly rarer. Exceptions to this trend might be found in a few societies where objections to induced abortion lead to restricted access to this procedure.

Child mortality. In recent decades sharp reductions in infant and child mortality have occurred worldwide, and further declines are expected in the future especially in those developing countries where mortality is still relatively high. In post-transitional societies typically only 1 or 2 percent of newborns die before reaching adulthood, and replacement births are therefore rare and only a minor factor in influencing fertility.

Gender preference. Son preference is still common in parts of Asia and the Middle East, but it will presumably decline as societies develop and increasingly treat boys and girls more equally. However, substantial son preference is still found in post-transitional populations including Taiwan, Korea, and China. The fertility impact of son preference is being eroded by sex-selective abortion, a relatively new practice that is growing rapidly in some Asian countries. Sexselective abortion reduces the sex ratio at birth and lowers fertility. It also raises replacement fertility, thus accelerating the trend to below-replacement fertility.

Rising age at childbearing. The fertility-depressing effect of this factor is present only as long as the age at childbearing keeps rising. In principle, this could be the case for decades, but eventually it will stop and at that time fertility will rise as the depressing effect is removed.

Involuntary family limitation and competing preferences. As societies move into the post-transitional phase, age at onset of childbearing and the proportion never marrying typically rise, as does the divorce rate. These trends raise the probability that individuals who marry are unable to achieve their desired family size because of the early onset of sterility or termination of marriage. Although informal cohabitation both before and after marriage is becoming more preva- 
lent, it not a child-producing substitute for marriage. In addition, if growing proportions of individuals never enter a marriage or stable union, then fertility could remain below replacement even if the DFS of married individuals remains 2 children. Until the causes of competing preferences are better understood it is difficult to forecast future trends in this factor.

The multiplicity of factors influencing fertility in post-transitional societies and the difficulty of projecting future trends in each make it virtually impossible to draw firm conclusions. As noted, the trend in desired family size is the most critical determinant of future fertility. If DFS drops below 2 then it is likely that fertility will do the same. Even in societies where desired fertility remains at about 2 children, fertility can remain below replacement for a prolonged period if the combined effects of the fertility-depressing factors outweigh the combined effects of the fertility-enhancing factors. There is, however, one fairly robust conclusion that can be drawn from the above analysis: the total fertility rate is likely to rise in the not too distant future in countries where the age at childbearing is now rising rapidly. Once this upward trend stops and the age at childbearing stabilizes, the fertility-inhibiting effect of this rise is removed. Fertility will then rise closer to the desired level. This trend has apparently been responsible in part for the rise in fertility in the United States (Bongaarts and Feeney 1998) and in Sweden in the late 1980s (Hoem 1990). A similar pattern might well occur in other post-transitional societies, where observed fertility is currently depressed by a timing effect. Where this happens, declines in population size will become less likely and population aging will be less rapid than would be the case without this upward adjustment. 


\section{Notes}

1. The replacement TFR depends on the level of mortality. It equals about 2.1 births in populations with low mortality but it can exceed 2.5 when mortality is high.

2. The Eurobarometer surveys asked the following question of men and women in 12 countries of the European Community: "[In your country] today what do you think is the ideal number of children for a family like yours or the one you might have?" Estimates based on this question are close to but slightly higher than those obtained for the number of children ultimately expected in recent Fertility and Family Surveys, and they are significantly lower than those obtained for the average number of children considered ideal by respondents in the World Values Surveys (van de Kaa 1998).

\section{References}

Abma J., A. Chandra, W. Mosher, and L. Peterson. 1997. Fertility, Family Planning and Women's Health: New Data from the 1995 National Survey of Family Growth. National Center for Health Statistics. Vital Health Statistics 23 (19).

Arnold, Fred. 1997. "Gender preferences for children: Findings from the Demographic and Health Surveys," in Proceedings of the XXIII IUSSP General Population Conference, Beijing. Liège: IUSSP.

Bankole, Akinrinola and Charles Westoff. 1995. "Childbearing attitudes and intentions," DHS Comparative Studies No.17. Calverton, MD: Macro International Inc.

Bongaarts, John. 1991. "The KAP-gap and the unmet need for contraception," Population and Development Review 17(2):293-313. 
- 1997. "Trends in unwanted childbearing in the developing world," Studies in Family Planning 28(4):267-277.

Bongaarts, John and Robert G. Potter. 1983. Fertility, Biology, and Behavior. New York: Academic Press.

Bongaarts, John and Griffith Feeney. 1998. "On the tempo and quantum of fertility," Population and Development Review 24(2):271-291.

Brass, W. 1974. "Perspectives in population prediction: Illustrated by the statistics of England and Wales," Journal of the Royal Statistical Society A, 137:55-72.

Caldwell, John C. 1982. Theory of Fertility Decline. New York: Academic Press.

Chowdhury, Mridul K. and Radheshyam Bairagi.1990. "Son preference and fertility in Bangladesh," Population and Development Review 16(4):749-757.

Coale, Ansley J. 1986. "Demographic effects of below-replacement fertility and their social implications," Population and Development Review 12 (Supp): 203-216.

Cohen, Barney and Mark Montgomery. 1997. From Death to Birth. Washington, D.C.: National Academy Press

Coleman, David. 1996. "New patterns and trends in European fertility: International and sub-national comparisons," in Europe's Population in the 1990's (David Coleman, ed.). Oxford University Press.

Council of Europe. 1996. Recent Demographic Developments in Europe. Belgium: Council of Europe Publishing.

Demeny, Paul 1997. "Replacement-level fertility: The implausible endpoint of the demographic transition," in Gavin W. Jones, Robert M. Douglas, John C. Caldwell, and Rennie M. D'Souza (eds.), The Continuing Demographic Transition. Oxford: Clarendon Press. 
Eurobarometer. 1991. "Desire for children," Eurobarometer 32.

Feeney, Griffith and Jingyuan Yu. 1987. "Period parity progression measures of fertility in China," Population Studies 41:77-102.

Feeney, Griffith, Feng Wang, Mingkun Zhou, and Baoyu Xiao, 1989. "Recent fertility dynamics in China: Results from the 1987 One Percent Population Survey," Population and Development Review 15(2):297-322.

Foster, Andrew. 1990. "Cohort analysis and demographic translation: A comparative study of recent trends in age specific fertility rates from Europe and North America," Population Studies 44:287-315.

Freedman, Ronald, Ming-Cheng Chang, and Te-Hsiung Sun. 1994. "Taiwan's transition from high fertility to below replacement levels," Studies in Family Planning 25(6):317-331.

Gray, Ronald. 1983. "The impact of health and nutrition on natural fertility," in R. Bulatao and R.D. Lee, eds., Determinants of Fertility in Developing Countries, Vol. 2. New York: Academic Press.

Henry, L. 1980. "Fertility of marriages: A new method of measurement," Population Studies Translation Series, No. 3. United Nations. Originally published 1953.

Heuser, Robert L. 1976. "Fertility tables for birth cohorts by color," DHEW Publication No. (HRA) 76-1152. Rockville, MD: National Center for Health Statistics.

Hoem, Jan M. 1990. "Social policy and recent fertility change in Sweden," Population and Development Review 16(4):735-748.

Knodel, John Vipan Prachuabmoh Ruffolo, Pakamas Ratanalangkarn, and Kua Wongboonsin. 1996. "Reproductive preferences and fertility trends in posttransition Thailand," Studies in Family Planning 27(6):307-318. 
Le Bras, Hervé. 1991. Marianne et les lapins: l'obsession demographique. Paris: Olivier Orban.

Lloyd, C.B. and S. Ivanov. 1988. "The effects of improved child survival on family planning practice and fertility," Studies in Family Planning 19(3):141-161.

Lutz, Wolfgang. 1996. "Future reproductive behavior in industrialized countries," in Wolfgang Lutz (ed.), The Future Population of the World: What Can We Assume Today? London: Earthscan Publications.

Mutharayappa, Rangamuthia, Minja Kim Choe, Fred Arnold, and T.K. Roy. 1997. "Son preference and its effect on fertility in India." National Family Health Survey Subject Reports No. 3. East-West Center Program on Population, Honolulu.

Ní Bhrolcháin, Máire. 1987. "Period parity progression ratios and birth intervals in England and Wales, 1941-1971: A synthetic life table analysis," Рориlation Studies 41(1):103-125.

Ní Bhrolcháin, Máire. 1992. "Period paramount? A critique of the cohort approach to fertility," Population and Development Review 18(4):599-629.

Page, H.J. 1977. "Patterns underlying fertility schedules: A decomposition by both age and marriage duration," Population Studies 30: 85-106.

Park, Chai Bin and Nam-Hoon Cho. 1995. "Consequences of son preference in a low-fertility society: Imbalance of the sex ratio at birth in Korea," Population and Development Review 21(1):59-84.

Preston, S.H. 1978. Introduction, in S.H. Preston, ed., The Effects of Infant and Child Mortality on Fertility. New York: Academic Press.

Pullum, T.W. 1980. "Separating age, period and cohort effects in white US fertility, 1920-70," Social Science Research 9:225-244.

Rallu, Jean-Louis and Laurent Toulemon. 1994. "Period fertility measures: The construction of different indices and their application to France, 194689," Population: An English Selection 6:59-94. 
Ryder, Norman B. 1956. "Problems of trend determination during a transition in fertility," Milbank Memorial Fund Quarterly 34(1).

Ryder, Norman B. 1959. "An appraisal of fertility trends in the United States," in Thirty Years of Research in Human Fertility: Retrospect and Prospect. New York: Milbank Memorial Fund, pp. 38-49.

Ryder, Norman B. 1964. "The process of demographic translation," Demography 1:74-82.

Ryder, Norman B. 1980. "Components of temporal variations in American fertility," in R.W. Hiorns, ed., Demographic Patterns in Developed Societies. London: Taylor \& Francis.

Ryder, Norman B. 1983. "Cohort and period measures of changing fertility," in R. Bulatao and R.D. Lee, eds., Determinants of Fertility in Developing Countries, Vol. 2. New York: Academic Press.

Ryder, Norman B. 1986. "Observations on the history of cohort fertility in the United States,” Population and Development Review 12(4):617-643.

Singh, Susheela and Renee Samara. 1996. "Early marriage among women in developing countries," International Family Planning Perspectives 22(4):148-175.

United Nations. 1996. World Population Prospects: The 1996 revision. Annex I: Demographic Indicators. New York.

van de Kaa, Dirk. 1987. "Europe's second demographic transition," Population Bulletin 42, no. 1:1-57.

1998. "Postmodern Fertility Preferences: From Changing Value Orientation to New Behavior." Working Papers in Demography, No. 74. Canberra: The Australian National University, Research School of Social Sciences.

Westoff, Charles, Charles Hammerslough, and Luis Paul. 1987. "The potential impact of improvements in contraception on fertility and abortion in Western countries," European Journal of Population 3:7-32. 
Westoff, Charles F. 1991. "Reproductive preferences: A comparative view," DHS Comparative Studies No. 3. Columbia, MD: Macro International and Institute for Resource Development.

Whelpton, Pascal K. 1954. Cohort Fertility: Native White Women in the United States. Princeton, NJ: Princeton University Press. [Reissued in 1973 by Kennikat Press, Port Washington, NY.]

World Health Organization 1995. "Task Force on the Prevention and Management of Infertility. Tubal infertility: Serologic relationship to past Chlamydial and gonococcal infection," Sexually Transmitted Diseases 22(2):7177. 


\title{
POLICY RESEARCH DIVISION WORKING PAPERS
}

\author{
Recent Back Issues
}

1996

*83 Sajeda Amin, Ian Diamond, and Fiona Steele, "Contraception and religious practice in Bangladesh."

84 John B. Casterline, Aurora E. Perez, and Ann E. Biddlecom, "Factors underlying unmet need for family planning in the Philippines."

85 Geoffrey McNicoll, "Governance of fertility transition: Regularity and duress."

*86 John Bongaarts, "Population pressure and the food supply system in the developing world."

87 Sajeda Amin, "Family structure and change in rural Bangladesh."
*88 John Bongaarts and Susan Cotts Watkins, "Social interactions and contemporary fertility transitions."

*89 Cynthia B. Lloyd and Mark R. Montgomery, "The consequences of unintended fertility for investments in children: Conceptual and methodological issues."

* 90 Zeba Sathar and Sonalde Desai, "Work patterns in rural Pakistan: Intersections between gender, family, and class."

*91 Mark R. Montgomery, "Learning and lags in mortality perceptions."

92 Ann E. Biddlecom, John B. Casterline, and Aurora E. Perez, "Men's and women's views of contraception."
93 James F. Phillips, Fred N. Binka, Martin Adjuik, Alex Nazzar, and Kubaze Frank Adazu, "The determinants of contraceptive innovation: A case-control study of family planning acceptance in a traditional African society."

94 John Bongaarts and Sajeda Amin, "Prospects for fertility decline and implications for population growth in South Asia."

95 Barbara S. Mensch and Cynthia B. Lloyd, "Gender differences in the

* No longer available schooling experiences of adolescents in low-income countries: The case of Kenya."

96 Martin Brockerhoff and Ellen Brennan, "The poverty of cities in the developing world."

97 Carol E. Kaufman, "Reproductive control in South Africa."

98 John Bongaarts, "Trends in unwanted childbearing in the developing world." 
99 Mary Arends-Kuenning, "How do family planning workers' visits affect women's contraceptive behavior in Bangladesh?"

100 Mark R. Montgomery and Cynthia B. Lloyd, "Excess fertility, unintended births, and children's schooling."

101 Mary Arends-Kuenning, "The equity and efficiency of doorstep delivery of contraceptives in Bangladesh."

102 Sajeda Amin, Ian Diamond, Ruchira T. Naved, and Margaret Newby, "Transi- tion to adulthood of female factory workers: Some evidence from Bangladesh."

*103 Margaret E. Greene and Ann E. Biddlecom, "Absent and problematic men: Demographic accounts of male reproductive roles."

104 Michael P. Todaro, "Urbanization, unemployment, and migration in Africa: Theory and policy."

105 Geoffrey McNicoll, "Population and poverty: A review and restatement."
106 Sajeda Amin and Gilda Sedgh, "Incentive schemes for school attendance in rural Bangladesh."

107 Martin Brockerhoff and Paul Hewett, "Ethnicity and child mortality in subSaharan Africa."

108 Ann E. Biddlecom and Bolaji M. Fapohunda, "Covert contraceptive use: Prevalence, motivations, and consequences."

109 John Bongaarts and Griffith Feeney, "On the quantum and tempo of fertility."

110 Barbara S. Mensch, Daniel Bagah, Wesley H. Clark, and Fred Binka, "The changing social environment for adoles- cents in the Kassena-Nankana District of northern Ghana: Implications for reproductive behavior."

111 Martin Brockerhoff and Ann Biddlecom, "Migration, sexual behavior, and HIV diffusion in Kenya."

112 Zeba A. Sathar and John B. Casterline, "The onset of fertility transition in Pakistan."

113 Geoffrey McNicoll, "Government and fertility in transitional and post-transitional societies."

114 John Bongaarts, "Fertility and reproductive preferences in post-transitional societies."

\footnotetext{
* No longer available
} 